
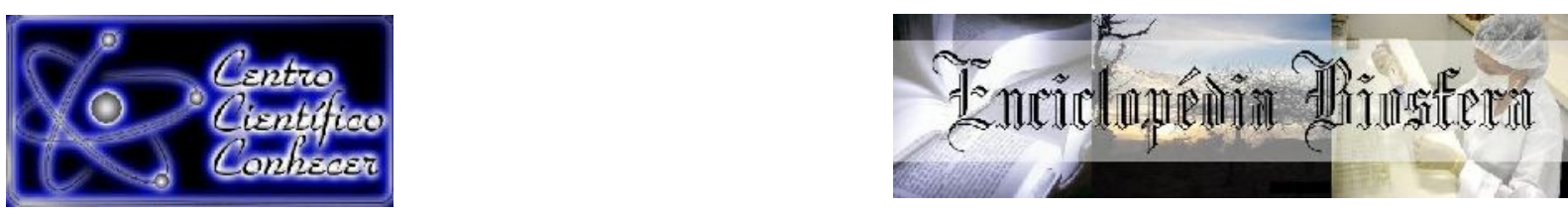

\title{
MANEJO QUÍMICO COM FUNGICIDA CRONNOS NO CONTROLE DAS DOENÇAS NA CULTURA DA SOJA ${ }^{1}$
}

Joaquim Júlio de Almeida Júnior ${ }^{1}$ Francisco Solano Araújo Matos ${ }^{2}$, Katya Bonfim Ataides Smiljanic ${ }^{3}$, Alexandre Caetano Perozini ${ }^{4}$, Adriano Bernardo Leal $^{5}$

1 Pós doutorando, UC - Universidade de Coimbra, joaquimjuliojr@gmail.com.

Coimbra, Portugal.

2 Professor Adjunto, Mestre em Fitopatologia. UniFimes-Centro Universitário de Mineiros; Goiás. Brasil.

3 Professora Adjunto, Mestre em Botânica. UniFimes-Centro Universitário de Mineiros; Goiás. Brasil.

4 Professora Titular, Doutor em Sistema de Produção. IFMT Campos São Vicente; Mato Grosso. Brasil.

5 Acadêmico do curso de Agronomia. UniFimes-Centro Universitário de Mineiros. Goiás. Brasil.

Recebido em: 06/04/2019 - Aprovado em: 10/06/2019 - Publicado em: 30/06/2019 DOI: 10.18677/EnciBio_2019A83

\begin{abstract}
O experimento foi conduzido pelo Núcleo de Estudo e Pesquisa em Fitotecnia no Município de Jataí, Estado de Goiás. A área experimental foi instalada em uma lavoura comercial de Soja cultivar da Nidera NS 7901 RR. Este trabalho teve como objetivo avaliar o posicionamento de estádio de aplicação do fungicida Cronnos (mancozebe + Picoxistrobina + Tebuconazol) para o manejo químico das doenças da soja e sua seletividade, conduzido a campo no sudoeste goiano. $O$ delineamento experimental foi em blocos casualizados com quatro repetições em esquema $11 \times 4 \times 1$. As variáveis tecnológicas levantadas foram produtividade de soja por hectare, massa de cem grãos e doenças de final de ciclo com suas respectivas datas de aplicação. Os programas de proteção com fungicidas em que o Cronnos foi utilizado em duas aplicações mostraram-se superior quando comparado a programas em que este fungicida foi utilizado em uma única aplicação. Isto porque, em dois programas em que o Cronnos foi utilizado em duas das quatro aplicações de fungicidas efetivadas. O rendimento de grãos foi em média superior ao rendimento obtido em seis programas em que o Cronnos foi aplicado uma única vez.
\end{abstract}

RESUMO

PALAVRAS-CHAVE: Controle de pragas. Fitossanitários. Glycine max. Produtividade.

1

$\square_{\text {Parte de pesquisa em andamento. }}$ 


\title{
CHEMICAL MANAGEMENT WITH FUNGICIDE CRONNOS IN THE CONTROL OF DISEASES IN THE SOYBEAN CROP
}

\begin{abstract}
The experiment was conducted by the Nucleus of Education and Research in Plant Science in the Municipality of Jataí, State of Goiás. The experimental area was installed in a commercial crop of soybean cultivar of Nidera NS 7901 RR. This work aimed to evaluate the application of the Cronnos fungicide (mancozebe + Picoxystrobin + Tebuconazol) for the chemical management of soybean diseases and its selectivity, conducted in the field in southwestern Goiás. The experimental design was in randomized blocks with four replicates in $11 \times 4 \times 1$ scheme. The technological variables surveyed were soybean yield per hectare, one hundred grain mass and end-of-cycle diseases with their respective application dates. Fungicide protection programs in which Cronnos was used in two applications proved superior when compared to programs in which Cronnos is used in a single application. This is because in two programs in which Cronnos was used in two of the four effective fungicide applications, the grain yield was on average higher than the yield obtained in six programs in which Cronnos was applied only once.
\end{abstract}

KEYWORDS: Pest control. Phytosanitary products. Glycine max. Productivity.

\section{INTRODUÇÃO}

A soja (Glycine max L.) pertencente à família Fabaceae, originária da China e teve no Brasil umas grandes expansões nas últimas décadas, se destacando como segundo maior produtor de soja e o que tem maior potencial para expandir a área cultivada. Para a safra 2018/19, a expectativa é de crescimento da área plantada em até $1,7 \%$ em relação à safra passada, chegando ao plantio de 35,8 milhões de hectares (CONAB, 2019). Porém, diversos fatores podem afetar produtividade da soja, dentre eles estão às doenças causadas por fungos que são favorecidas pelas condições climáticas como elevadas temperaturas e umidade, implantação da monocultura e outras práticas inadequadas.

Estima-se que a produção de soja no Brasil poderia ser até $30 \%$ maior se não fossem os danos causados pelas doenças de final de ciclo como a mancha parda, (Septoria glycines), cercospora (Cercospora kikuchii) além da ferrugem asiática (Phakopsora pachyrhizi).

Os sintomas iniciais provocados pela cercospora (Cercospora kikuchii) são pontos de coloração castanho-avermelhadas que evoluem para uma cor púrpura-escura que pode se estender por toda a superfície das folhas infectadas. Nas infecções severas, ocorre um desfolhamento prematuro, confundido com senescência precoce (EMBRAPA, 2013a). 
$\mathrm{Na}$ mancha parda (Septoria glycines) as folhas inicialmente verdes apresentam pequenas pontuações, menores de $1 \mathrm{~mm}$, de cor parda, que, ao se desenvolverem, formam manchas maiores, que apresentam halos amarelados e centro de contornos angulares, de coloração parda na face superior e rosada na face inferior da folha. Quando ocorrem infecções severas, as manchas podem apresentar tamanho suficiente para cobrir as superfícies, superior e inferior das folhas, provocando desfolha e maturação prematura e consequente redução da produtividade (EMBRAPA, 2013a).

A antracnose (Colletotrichum truncatum) é disseminada por meio de sementes contaminadas, restos de cultura, pelo vento e pela chuva. Requer condições favoráveis para o desenvolvimento como altas densidades populacionais em associação com a umidade prolongada por chuvas frequentes ou alta umidade relativa e ainda uma temperatura que varie entre $18^{\circ} \mathrm{C}$ e $25^{\circ} \mathrm{C}$. Os sintomas podem ser visualizados em todos os estádios de desenvolvimento da planta (vegetativos e reprodutivos) e em todos os órgãos (cotilédones, pecíolos, folhas, hastes e vagens). Mesmo tratadas, as sementes infectadas em ambiente úmido causam o tombamento das plântulas que apresentam sintomas como necrose nos cotilédones. Em plantas desenvolvidas poderá ocorrer o estrangulamento e necrose dos pecíolos, nervuras, pedúnculo, hastes, vagens e a desfolha precoce com comprometimento da formação das vagens que podem até serem perdidas (GRIGOLLI; GRIGOLLI, 2018).

A ferrugem asiática (Phakopsora pachyrhizi Syd. \& P.Syd) é considerada como uma das doenças mais importantes da soja que se manifesta na superfície das folhas em urédias, nome dado a saliências que correspondem à estrutura de reprodução do fungo. Utilização de cultivares com ciclo precoce, eliminação de plantas de soja voluntárias, respeito ao vazio sanitário são recomendações para a redução dos riscos de danos à cultura causados por fungos além do uso de fungicidas (SIMÕES et al., 2018).

Este trabalho teve como objetivo avaliar o posicionamento de estádio de aplicação do fungicida Cronnos (mancozebe + Picoxistrobina + Tebuconazol) para o manejo químico das doenças da soja e sua seletividade, conduzido a campo no sudoeste goiano.

\section{MATERIAL E METODOS}

O experimento foi conduzido pelo Núcleo de Estudo e Pesquisa em Fitotecnia no Município de Jataí, Estado de Goiás, em área experimental com as coordenadas geográficas de referência: latitude sul 1752'39.74" e longitude oeste $51^{\circ} 45^{\prime} 34.92 "$.

A área experimental foi instalada em uma lavoura comercial de Soja cultivar da Nidera NS 7901 RR, com semeadura em 31 de outubro de 2018, na safra 2018/2019. As adubações e demais tratamentos, até a demarcação do experimento, foram efetuadas de acordo com as recomendações técnicas.

As aplicações de fungicidas na área experimental foram efetuadas de acordo com cada tratamento previamente estabelecido. A área experimental foi protegida com aplicações de inseticidas de maneira que a produção de grãos 
fosse afetada somente pela maior ou menor eficiência de controle de doenças pelos tratamentos fungicidas.

A região possui clima classificado por Köppen (2013) tipo Aw, tropical úmido, definido em duas estações, verão chuvoso úmido e inverno muito seco. O índice pluviométrico anual fica em torno de uma média anual de 1.910 milímetros, tendo uma média de temperatura anual próximo dos $25^{\circ} \mathrm{C}$ e média de $67 \%$ de umidade do ar relativa (Figura 1).

A predominância das chuvas ocorre nos meses de outubro até março, com uma média acentuada e um maior volume nos meses de dezembro até fevereiro, e no anverso, o menor índice de chuva, se encontra nos meses de junho até agosto com uma média de 28 milímetros.

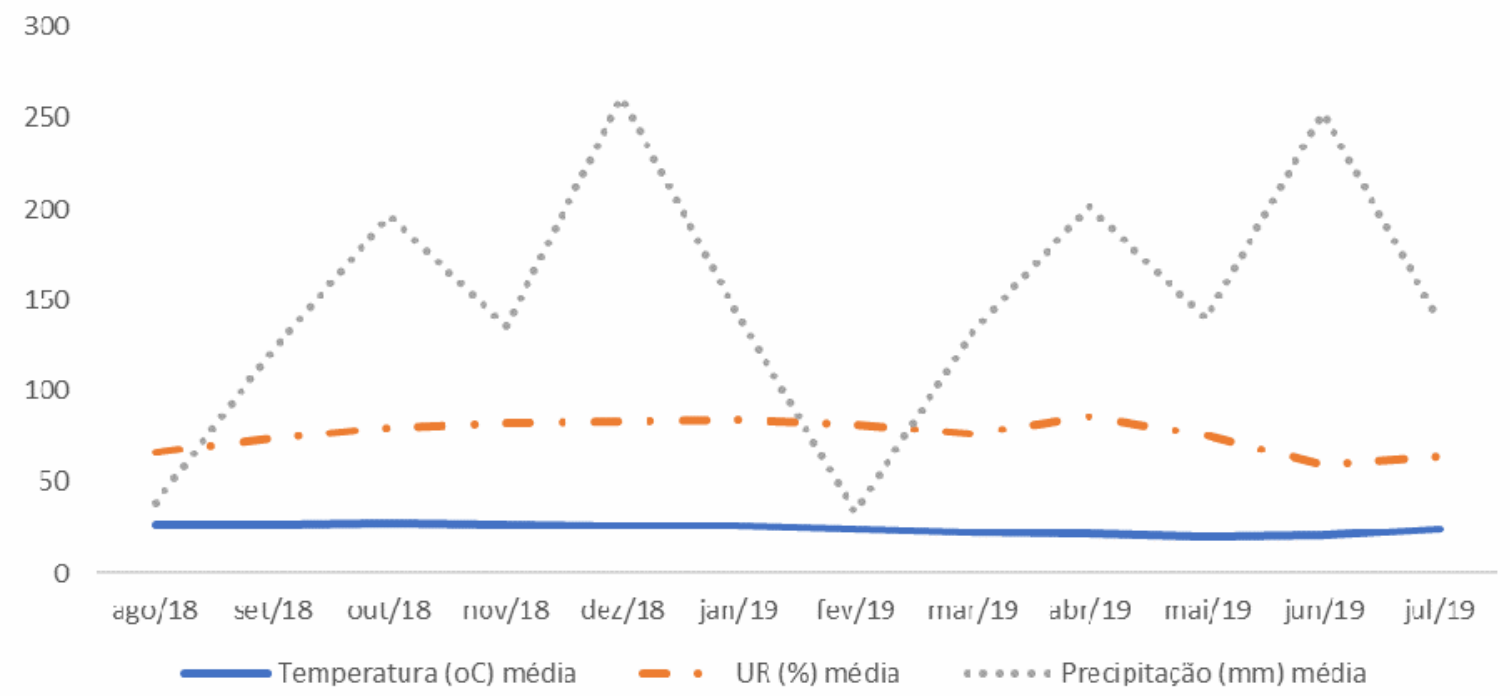

FIGURA 1. Temperatura máxima $\left(\mathrm{C}^{\circ}\right)$ médias mensais, umidade relativa do ar (\%) e precipitação pluvial (mm) acumuladas na safra 2018/2019 na área experimental, conduzido pelo Núcleo de Ensino e Pesquisa em Fitotecnia, instalada em uma lavoura comercial de Soja, cultivar da Nidera NS 7901 RR. Jataí. Estado de Goiás. Safra 2018/2019.

FONTE: AGRITEMPO - Sistema de Monitoramento Agrometeorológico Jataí / INMET. Município de Jataí, Estado de Goiás. 2018.

O solo na área experimental é classificado pelo Sistema Brasileiro de Classificação de Solo (EMBRAPA, 2013b) como tipo Neossolo Quartzarênico, com uma textura baseada em areia, no qual anteriormente era ocupado com vegetação predominante de Cerrado e foi trabalhada por culturas perenes por volta de 16 anos.

O solo da área experimental possui atributos que foram avaliados para implantação da pesquisa no intuito de observar as características físicas e químicas. Nas análises foram determinados $\mathrm{pH}, \mathrm{P}, \mathrm{K}, \mathrm{Ca}, \mathrm{Mg}, \mathrm{H}+\mathrm{Al}, \mathrm{Al}, \mathrm{S} . \mathrm{B}, \mathrm{V}$ (\%) e M.O. entre as profundidades de zero a 20 centímetros e de 20 a 40 
centímetros de profundidades (RAIJ et al., 2001). As amostras foram analisadas no laboratório de solos da instituição de ensino de Mineiros, estado de Goiás (Tabela 1).

TABELA 1. Teores de nutrientes obtidos da análise do solo, referente a área experimental, instalada em uma lavoura comercial de soja, cultivar Desafio RR em trabalho conduzido pelo Núcleo de Estudo e Pesquisa em Fitotecnia. Jataí. Estado de Goiás. Safra 2018/2019.

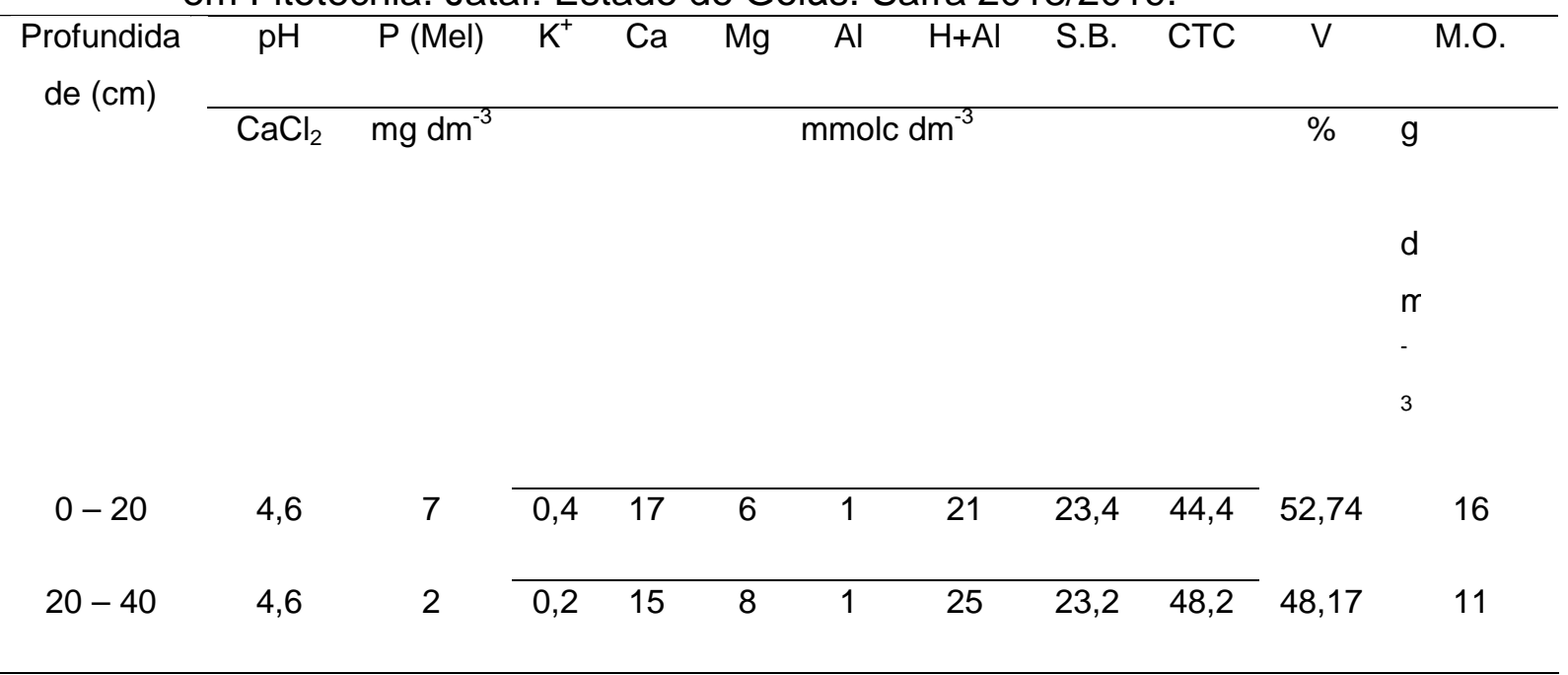

FONTE: Dados da pesquisa, 2019.

O delineamento experimental foi em blocos casualizados com quatro repetições, em esquema $11 \times 4 \times 1$ "onze tratamentos, quatro épocas de aplicação em uma variedade de soja" e a parcela experimental foi constituída de uma área com 3 metros de largura (aproximadamente seis linhas de plantio espaçadas de 0,45 metros) por 7 metros de comprimento. Na área central da parcela, constituída de 1 metro (duas fileiras centrais) por 5 metros $\left(5 \mathrm{~m}^{2}\right)$, foram tomados os dados de severidade de doenças e de produção. Os tratamentos consistiram da combinação de um programa padrão de aplicação de fungicidas, repetido em todos os tratamentos, associados a aplicações de diferentes fertilizantes.

No programa padrão foram utilizadas quatro aplicações de fungicidas recomendados para as doenças prevalentes no Sudoeste de Goiás.Estes fungicidas foram aplicados no estádio reprodutivo (a)=V4-V5 em 07-12-2018; (b)=R2-R3 em 23-12-2018; (c)=R5.1 em 09-01-2019; (d)=R5.3 em 24-01-2019;). Em adição à proteção fungicida foi aplicado um fertilizante químico "Expert Grow".

O nível de doença foi avaliado em cada parcela experimental tomando-se quatro plantas escolhidas ao acasoe em cada planta foi avaliada a parte inferior, mediana e superior. As severidades das doenças foram representadas pela média das leituras de severidade em 12 folhas.A leitura de severidade foi efetuada com o auxílio de escalas diagramáticas específicas para cada doença. 
Para a avaliação da ferrugem asiática da soja (Phakopsora pachyrhizi) foi utilizada uma escala diagramática com as seguintes representações de áreas foliares infectadas (\%AFI): 0,6\%;2,0\%; 7,0\%; 18,0\%; 42,0\%; 78,5\%, conforme escala proposta por Godoy et al. (2006). Na avaliação das doenças de final de ciclo (DFC) causadas por Cercospora kikuchi e Septoria glycines foi utilizada uma escala diagramática com os níveis: $0 ; 2,4 ; 15,2 ; 25,9 ; 40,5 \%$ e $66,6 \%$ conforme proposto por Soares et al. (2009). Para mancha alvo causada por Corynespora cassiicola foi utilizada a escala com os graus: $1 \%$; $2 \% ; 5 \%$; $9 \%$; 19\%; 33\% e 52\% de área foliar infectada (AFI) conforme Soares et al. (2009).

A avaliação da desfolha causada por doenças foi realizada utilizando-se uma escala diagramática com os níveis de $100 \% ; 85 \% ; 65 \% ; 45 \% ; 15 \%$ e $5 \%$ de desfolha proposta por Hirano et al. (2010). A percentagem de desfolha foi obtida estimando-se uma nota representativa da parcela como um todo. Os parâmetros produtivos foram obtidos na fase de colheita. Para a população final de plantas foram contadas todas as plantas da área útil da parcela $\left(0,9 \times 5 \mathrm{~m}=4,5 \mathrm{~m}^{2}\right)$. Os grãos de soja foram colhidos e secos ao sol de modo a reduzir e uniformizar as possíveis diferenças de umidades entre as parcelas.

As alturas de plantas e altura de primeira vagem e o número de vagens por planta foram obtidas a partir das medições em 3 plantas por parcela. O tratamento controle foi conduzido sem fungicida, e sem a adição de nenhum fertilizante químico. Os tratamentos foram constituídos por aplicações de fungicidas e a descrição completa dos tratamentos está relacionada na Tabela 2.

TABELA 2.Descrição dos tratamentos utilizados na área experimental em trabalho conduzido pelo Núcleo de Estudo e Pesquisa em Fitotecnia, instalada em uma lavoura comercial de Soja, cultivar da Nidera NS 7901 RR. Jataí. Estado de Goiás. Safra 2018/2019.

\begin{tabular}{|c|c|c|c|c|c|c|c|}
\hline TRAT & FA & $\begin{array}{l}\text { Fungicidas } \\
\text { MC.01 }\end{array}$ & $\begin{array}{l}\text { Fertilizantes } \\
\text { MC.02 }\end{array}$ & $\begin{array}{l}\text { Adjuvantes } \\
\text { MC.03 }\end{array}$ & $\begin{array}{l}\text { Dose } \\
\mathrm{g} \mathrm{ml} \mathrm{ha}^{-1} \\
\text { MC. } 01\end{array}$ & $\begin{array}{l}\text { Dose } \\
\text { g ml h a }{ }^{-1} \\
\text { MC. } 02\end{array}$ & $\begin{array}{l}\text { Dose } \\
\text { g ml h a } a^{-1} \\
\text { MC.03 }\end{array}$ \\
\hline $\begin{array}{l}01 \\
01 \\
01 \\
01\end{array}$ & $\begin{array}{l}\text { A } \\
\text { B } \\
\text { C } \\
\text { D }\end{array}$ & $\begin{array}{l}\text { Test.N.Pulv } \\
\text { Test.N.Pulv } \\
\text { Test.N.Pulv } \\
\text { Test.N.Pulv }\end{array}$ & & & & & \\
\hline $\begin{array}{l}02 \\
02\end{array}$ & $\begin{array}{l}A \\
B\end{array}$ & $\begin{array}{l}\text { Fox } \\
\text { Elatus }\end{array}$ & & Aureo & $\begin{array}{l}400 \\
200\end{array}$ & & 200 \\
\hline 02 & $\mathrm{~B}$ & Cypress & & Nimbus & 300 & & 500 \\
\hline 02 & C & Aproach Prima & & & 300 & & \\
\hline 02 & C & Unizeb Gold & & Nimbus & 1500 & & 500 \\
\hline 02 & D & Aproach Prima & & & 300 & & \\
\hline 02 & $\mathrm{D}$ & Unizeb Gold & & Nimbus & 1500 & & 500 \\
\hline 03 & A & Fox & & Aureo & 400 & & 200 \\
\hline 03 & $B$ & Cypress & & Nimbus & 300 & & 500 \\
\hline 03 & $B$ & Elatus & & & 200 & & \\
\hline 03 & C & Cronnos & & Rumba & 2350 & & 500 \\
\hline 03 & $\mathrm{D}$ & Cronnos & & Rumba & 2350 & & 500 \\
\hline 04 & A & Fox & & Aureo & 400 & & 200 \\
\hline 04 & $B$ & Cronnos & & Rumba & 2350 & & 500 \\
\hline 04 & C & Aproach Prima & & & 300 & & \\
\hline 04 & C & Unizeb Gold & & Nimbus & 1500 & & 500 \\
\hline 04 & $\mathrm{D}$ & Aproach Prima & & & 300 & & \\
\hline 04 & D & Unizeb Gold & & Nimbus & 1500 & & 500 \\
\hline 05 & $A$ & Cronnos & & Rumba & 2350 & & 500 \\
\hline 05 & B & Elatus & & & 200 & & \\
\hline 05 & B & Cypress & & Aureo & 300 & & 200 \\
\hline 05 & C & Aproach Prima & & & 300 & & \\
\hline 05 & C & Unizeb Gold & & Nimbus & 1500 & & 500 \\
\hline 05 & D & Aproach Prima & & & 300 & & \\
\hline 05 & $\mathrm{D}$ & Unizeb Gold & & Nimbus & 1500 & & 500 \\
\hline
\end{tabular}




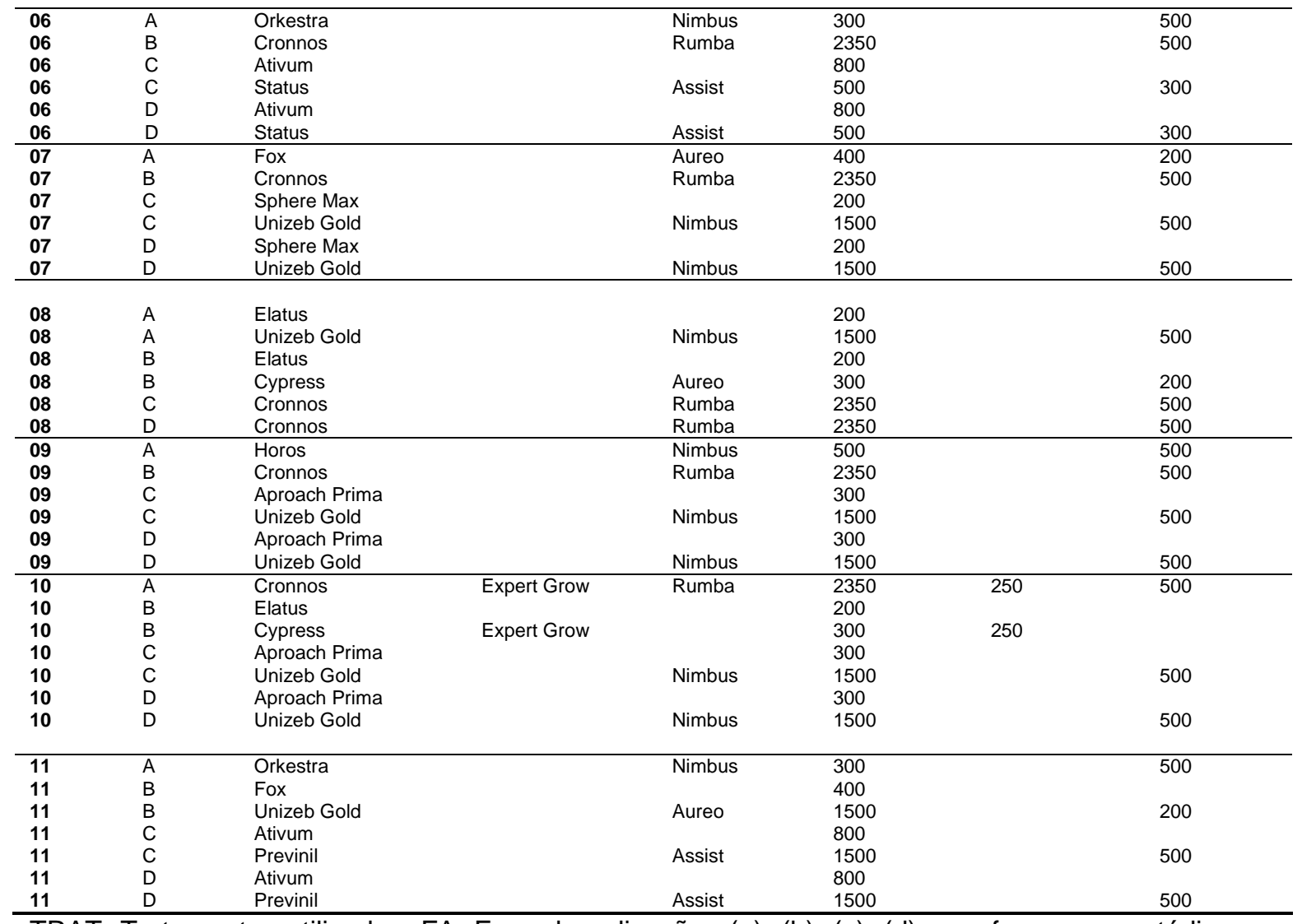

TRAT: Tratamentos utilizados; FA: Fase de aplicações (a), (b), (c), (d) se referem aos estádios fisiológicos e datas de aplicações: (a)=V4-V5 em 07-12-2018; (b)=R2-R3 em 23-12-2018; (c)=R5.1 em 09-01-2019; (d)=R5.3 em 24-01-2019; MC: Marca Comercial dos produtos químicos; Dose $\mathrm{g} \mathrm{ml} \mathrm{ha}^{-1}$ : Dose dos produtos em gramas (g) ou mililitros (ml) por hectare.

FONTE: Dados da pesquisa, 2019.

\section{RESULTADOS E DISCUSSÃO}

Não houve diferença significativa para a produtividade em sacas por hectare, entre os tratamentos (Tabela 3). Para as produtividades estimadas situaram-se entre 66,0 e 74,4 sacos de $60 \mathrm{Kg}$ por hectare para os tratamentos (T02) ao (T11), com utilização de proteção química de fungicidas, enquanto que o tratamento (T01) controle sem proteção química de fungicidas propiciou uma produtividade média estimada de 55,4 sacos de $60 \mathrm{Kg} \mathrm{ha}^{-1}$. Em trabalho realizado por Matos et al. (2017) com diferentes fungicidas, foi encontrada produtividade semelhante as encontradas neste trabalho.

Não foi possível detectar a ocorrência de diferença significativa para massa de cem grãos, entre os tratamentos testados (Tabela 3). Porém, com uso de proteção química de fungicidas ocorreram variações nos pesos da massa de cem grãos, em que o tratamento (T01) controle, sem proteção fúngica obteve o valor médio de 17,2 gramas por cem sementes. O oposto, isto é, o tratamento com melhor peso de cem sementes foi encontrado no tratamento (T10) com peso de 18,3 gramas. Em trabalho realizado por Matos et al. (2016) as variáveis peso de mil grãos ficaram semelhantes as encontradas neste trabalho. 
A proteção química contra doenças nos tratamentos fungicidas e tratos culturais como a proteção química com inseticidas e a fertilização mineral do solo permitiram a obtenção de altas produtividades na cultura da soja implantada neste trabalho.

TABELA 3. Médias dos índices da evolução de severidade representadas pelas porcentagens (\%) de área foliar infectada (\%AFI) por DFC sob condições de campo, entre as datas 21/12/2018 a 02/02/2019, em trabalho conduzido pelo Núcleo de Estudo e Pesquisa em Fitotecnia, instalada em uma lavoura comercial de Soja, cultivar da Nidera NS 7901 RR. Jataí. Estado de Goiás. Safra 2018/2019.

\begin{tabular}{ccc}
\hline TRAT & P Scha $^{-1}$ & MCG $(\mathrm{g})$ \\
\hline T01 & 55,4 & 17,2 \\
T02 & 73,5 & 17,5 \\
T03 & 74,4 & 17,8 \\
T04 & 69,0 & 18,0 \\
T05 & 67,4 & 17,2 \\
T06 & 66,8 & 16,4 \\
T07 & 66,8 & 17,4 \\
T08 & 69,0 & 18,1 \\
T09 & 66,5 & 18,0 \\
T10 & 69,2 & 18,3 \\
T11 & 66,0 & 17,0 \\
\hline
\end{tabular}

Valores sem letra, na coluna, não diferem estatisticamente a $5 \%$ de probabilidade pelo teste de Tukey.TRAT: Tratamentos utilizados; P Sc ha ${ }^{-1}$ : Produtividade de soja por hectare em sacas de $60 \mathrm{Kg}$; MCG: Massa de cem grãos (g).

FONTE: Dados da pesquisa, 2019.

Na variável tecnológica doenças de final de ciclo, não foi possível verificar diferença significativa entre os tratamentos utilizados (Tabela 4). Resultado semelhante foi encontrado por Matos et al., (2017). Problemas fitossanitários foram observados e se destacam as doenças de final de ciclo (DFC) causadas pelo complexo de patógenos Septoria glycines e ou Cercospora kikuchi, a antracnose causada por Colletotrichum truncatum, a mancha alvo causada por Corynespora cassiicola e a ferrugem asiática da soja (FAS) causada por Phakopsora pachyrhizi. As doenças antracnose, mancha alvo e ferrugem asiática da soja foram detectadas a partir da fase de enchimento de grãos e se mantiveram em baixos níveis de severidade. A FAS não foi detectada, neste trabalho, até a última avaliação de doenças que foi efetuada em 02-02-2019.

As DFC foram detectadas na fase inicial de florescimento (21-12-18), em plantas com 6 a 7 trifólios. Foram visualizados sinais principalmente na folha primaria apresentando nível de infecção abaixo de 5\% de área foliar infectada (\%AFI). Entre os problemas fitossanitários observados destacam-se as DFC em função da maior severidade e maior período de exposição da planta ao ataque do patógeno quando comparado ás outras doenças. 
Considerando que as cultivares de soja no mercado apresentam maior ou menor suscetibilidade às DFC e avaliando o nível de severidade das doenças no tratamento controle (T01) infere-se que as condições do experimento não foram muito favoráveis para as DFC. Isto porque os índices de severidade, quantificados em porcentagem de área foliar infectada (\%AFI) não ultrapassaram o nível de $10 \%$ de infecção foliar, situando-se entre 0,1 e 1,4\% de AFI (Tabela 4). Estes níveis de doenças, entretanto, podem ser considerados relativamente importantes na determinação da produtividade de grãos, e, portanto, para a avaliação da eficiência dos tratamentos fungicidas para o controle de doenças. Ribeiro et al. (2016) trabalhando com fungicidas em doenças de final de ciclo encontraram resultados semelhantes aos deste trabalho.

TABELA 4. Médias dos índices da evolução de severidade representados pelas porcentagens (\%) de área foliar infectada (\%AFI) por DFC sob condições de campo, entre as datas 21/12/2018 a 02/02/2019, em trabalho conduzido pelo Núcleo de Estudo e Pesquisa em Fitotecnia, instalado em uma lavoura comercial de Soja, cultivar da Nidera NS 7901 RR. Jataí. Estado de Goiás. Safra 2018/2019.

\begin{tabular}{ccccccc}
\hline TRAT & $\begin{array}{c}\text { DFC } \\
21 / 12 / 18\end{array}$ & $\begin{array}{c}\text { DFC } \\
04 / 01 / 19\end{array}$ & $\begin{array}{c}\text { DFC } \\
11 / 01 / 19\end{array}$ & $\begin{array}{c}\text { DFC } \\
18 / 01 / 19\end{array}$ & $\begin{array}{c}\text { DFC } \\
25 / 01 / 19\end{array}$ & $\begin{array}{c}\text { DFC } \\
02 / 02 / 19\end{array}$ \\
\hline T01 & 1,4 & 1,0 & 0,2 & 1,2 & 0,5 & 0,8 \\
T02 & 0,2 & 0,2 & 0,1 & 0,1 & 0,2 & 0,2 \\
T03 & 0,1 & 0,1 & 0,0 & 0,1 & 0,2 & 0,2 \\
T04 & 0,1 & 0,1 & 0,1 & 0,2 & 0,1 & 0,4 \\
T05 & 0,3 & 0,2 & 0,1 & 0,2 & 0,1 & 0,4 \\
T06 & 0,2 & 0,2 & 0,7 & 0,3 & 0,3 & 0,6 \\
T07 & 0,2 & 0,2 & 0,4 & 0,3 & 0,1 & 0,2 \\
T08 & 0,1 & 0,1 & 0,0 & 0,2 & 0,1 & 0,2 \\
T09 & 0,1 & 0,2 & 0,1 & 0,1 & 0,1 & 0,3 \\
T10 & 0,4 & 0,1 & 0,2 & 0,1 & 0,1 & 0,1 \\
T11 & 0,2 & 0,2 & 0,1 & 0,2 & 0,2 & 0,2 \\
\hline
\end{tabular}

Valores sem letra, na coluna, não diferem estatisticamente a $5 \%$ de probabilidade pelo teste de Tukey.TRAT: Tratamentos utilizados; DFC-Doenças de final de ciclo e respectivas datas de aplicação.

FONTE: Dados da pesquisa, 2019.

\section{CONCLUSÕES}

Considerando as condições verificadas a campo, no Sudoeste de Goiás, especialmente as condições relativas às espécies de fungos fitopatógenos prevalentes e a dinâmica do inóculo para a safra de verão de soja de 2018/2019, pode-se concluir que os programas utilizados de proteção com a presença do fungicida Cronnos demonstrou superior aos outros programas em que este mesmo fungicida foi utilizado em uma única aplicação. Isto é, onde o Cronnos foi aplicado duas vez, "dois estádios" a produtividade de grãos foi em média superior aos outros programas quando o fungicida Cronnos foi aplicado uma única vez 


\section{AGRADECIMENTOS}

Ao Núcleo de Estudo e Pesquisa em Fitotecnia por contribuir com informações técnicas para condução do projeto e aos funcionários da EMATER de Jataí por contribuir com mão de obra especializada. A todos os acadêmicos do curso de Agronomia pela participação no desenvolvimento deste projeto.

REFERÊNCIASAGRITEMPO - Sistema de Monitoramento Agrometeorológico Mineiros / INMET. Município de Mineiros, Estado de Goiás. 2018. Disponível em< http://agrometeorologia.seagro.to.gov.br/rede-demonitoramento/inmet/> Acessado: 01 de janeiro de 2019.

CONAB. Companhia Nacional de abastecimento. Acompanhamento da safra brasileira - grãos, v. 6 Safra 2018/19 - Quarto levantamento, Brasília, p. 1-126, 2019. ISSN 2318-6852 Disponível em <https://www.conab.gov.br/infoagro/safras/graos> Acessado em: 26 de janeiro de 2019.

EMBRAPA. Centro Nacional de Pesquisa de Soja. Tecnologias de produção de soja - região central do Brasil, 2014. Londrina: Embrapa Soja, (Sistemas de Produção / Embrapa Soja, 265 p. 2013a. ISSN 2176- 2902; n.16, outubro de 2013). $\quad$ Disponível <https://ainfo.cnptia.embrapa.br/digital/bitstream/item/95489/1/SP-16-online.pdf> Acessado em 23 de janeiro de 2019.

EMBRAPA. Empresa Brasileira de Pesquisa Agropecuária. Sistema Brasileiro de Classificação de Solos. Brasília, 3ª edição, 353 p. 2013b. ISBN 978-857035-198-2.

GODOY, C.V; KOGA, L.J; CANTERI, M.G. Diagrammatic scale for assessment of soybean rust severity. Fitopatologia Brasileirav.31, n. 1, p. 63-68, 2006. Disponivel: <http://dx.doi.org/10.1590/S010041582006000100011>

GRIGOLLI, J. F. J; GRIGOLLI, M. M. K. Manejo de Doenças na Cultura da Soja. Tecnologia e Produção: Soja 2017/2018. p.1-15, 2018. Disponível em < http://www.fundacaoms.org.br/base/www/fundacaoms.org.br/media/attachments/ 303/303/5bf01cc3a7885009c9e47176f153fe5e967c6cb20f243_06-manejo-dedoencas-na-cultura-da-soja-somente-leitura.pdf> Acessado em 14 de maio de 2019.

HIRANO, M.; HIKISHIMA; SILVA, A. J.; XAVIER, S.A.; GIOVANETTI, C. Validação de escala diagramática para estimativa de desfolha provocada pela ferrugem asiática em soja. Summa Phytopathologica. Botucatu, v.36, n.3, p.248-250, $2010 . \quad$ Disponível em <http://www.scielo.br/scielo.php?script=sci_abstract\&pid=S0100- 
$54052010000300012 \&$ Ing=en\&nrm=iso\&tlng=pt $>$ Acessado em 25 de outubro de 2018.

KÖPPEN, G; ALVARES, C.A; STAPE, J.L; SENTELHAS, P.C; DE GONÇALVES, M;

LEONARDO, J; GERD, S; Köppen's Climate Classification Map for Brazil. Meteorologische Zeitschrift .2013. 711-728. DOI: https://doi.org/10.1127/09412948/2013/0507

MATOS, F. S. A; ALMEIDA JÚNIOR, J. J; SMILJANIC, K. B. A. Eficiência de fungicidas para o controle da ferrugem asiática da soja (Phakopsora pachyrhizi), safra 2015/16. I Colóquio Estadual de Pesquisa Multidisciplinar, v.1, p.1-10. 2016. ISSN 2527-2500. Disponível em < http://publicacoes.unifimes.edu.br/index.php/coloquio/article/view/24> Acessado em 13 de dezembro de 2018.

MATOS, F. S. A; ALMEIDA JÚNIOR, J. J; SMILJANIC, K. B. A; MENDONÇA, A. F. MARTINS FILHO; M. B. SILVA. A. R. Fungicida cronnos para o manejo químico das doenças da soja, a campo, em Jataí - GO, safra agrícola 2016/2017. II Colóquio Estadual de Pesquisa Multidisciplinar, v.2, p.1-12. 2017. ISSN 2527-2500. Disponível < http://publicacoes.unifimes.edu.br/index.php/coloquio/article/view/231> Acessado em 10 de dezembro de 2018.

RAIJ, B. V; ANDRADE, J.C.; CANTARELLA, H.\& QUAGGIO, J.A. (Ed.). Análise química para avaliação da fertilidade de solos tropicais. Campinas: Instituto agronômico, p.285, 2001. Disponível: https://www.bdpa.cnptia.embrapa.br/consulta/busca?b=ad\&id=14135\&biblioteca =CNPSO\&busca=autoria:\%22RAIJ,\%20B.\%20van.\%22\&qFacets=autoria:\%22R AlJ,\%20B.\%20van.\%22\&sort=\&paginacao=t\&paginaAtual $=1$

RIBEIRO, F. C; ERASMO, A. L; MORAES, E. B; CERQUEIRA, F. B; MATOS, E. P; ROCHA, F. S. Fungicidas aplicados na cultura da soja visando o controle da ferrugem asiática no estado do Tocantins. Revista Cultivando o Saber, v. 9, $\mathrm{n}^{\circ} 2$, p.198-209, 2016. ISSN 2175-2214. Disponível em <https://www.fag.edu.br/upload/revista/cultivando_o_saber/57a3b0899b617.pdf> Acessado em 15 de janeiro de 2019.

SIMÕES, K.; HAWLIK, A.; REHFUS, A.; GAVA, F.; STAMMLER, G. First detection of a SDH variant with reduced SDHI sensitivity in Phakopsora pachyrhizi. Journal of Plant Diseases and Protection. v.125, p.21-26, 2018. Disponível em <https://link.springer.com/article/10.1007/s41348-017-0117-5> Acessado em 05 de setembro de 2018.

SOARES, R. M; GODOY, C. V; OLIVEIRA, M. C. N. Escala diagramática para avaliação da severidade da mancha alvo da soja. Tropical PlantPathology. v. 
34, n.5. p.333-338, 2009. Disponível $e m<$ http://www.scielo.br/pdf/tpp/v34n5/v34n5a07.pdf> Acessado em 31 de janeiro de 2019. 